\title{
The roles of cognitive abilities and hearing acuity in older adults' recognition of words taken from fast and spectrally reduced speech
}

\author{
Esther Janse $^{1, *}$ (iD) and Sible J. Andringa ${ }^{2}$ \\ ${ }^{1}$ Radboud University, Nijmegen; and Max Planck institute for Psycholinguistics, Nijmegen and ${ }^{2}$ Amsterdam \\ Centre for Language and Communication, University of Amsterdam \\ ${ }^{*}$ Corresponding author: Esther Janse, Center for Language Studies, Radboud University, Postbus 9103, 6500 \\ HD Nijmegen, The Nethlands. E-mail: e.janse@let.ru.nl
}

(Received 12 September 2019; revised 22 December 2020; accepted 12 January 2021; first published online 08 February 2021)

\begin{abstract}
Previous literature has identified several cognitive abilities as predictors of individual differences in speech perception. Working memory was chief among them, but effects have also been found for processing speed. Most research has been conducted on speech in noise, but fast and unclear articulation also makes listening challenging, particularly for older listeners. As a first step toward specifying the cognitive mechanisms underlying spoken word recognition, we set up this study to determine which factors explain unique variation in word identification accuracy in fast speech, and the extent to which this was affected by further degradation of the speech signal. To that end, 105 older adults were tested on identification accuracy of fast words in unaltered and degraded conditions in which the speech stimuli were low-pass filtered. They were also tested on processing speed, memory, vocabulary knowledge, and hearing sensitivity. A structural equation analysis showed that only memory and hearing sensitivity explained unique variance in word recognition in both listening conditions. Working memory was more strongly associated with performance in the unfiltered than in the filtered condition. These results suggest that memory skills, rather than speed, facilitate the mapping of single words onto stored lexical representations, particularly in conditions of medium difficulty.
\end{abstract}

Keywords: aging and language; hearing impairment; individual differences; memory and language; speech perception

It has long been known that people vary considerably in their ability to process spoken language, even if their objective hearing sensitivity is taken into account (Jerger, Jerger, \& Pirozzolo, 1991; Middelweerd, Festen, \& Plomp, 1990; van Rooij \& Plomp, 1990, 1992). These individual differences may already exist when listening is relatively easy for all participants, but come out more clearly when listening is more challenging, as is the case when speech is spoken rapidly and in a conversational manner or when target

(C) The Author(s), 2021. Published by Cambridge University Press. This is an Open Access article, distributed under the terms of the Creative Commons Attribution licence (http://creativecommons.org/licenses/by/4.0/), which permits unrestricted re-use, distribution, and reproduction in any medium, provided the original work is properly cited. 
speech is masked by environmental noise. Individual-differences research can inform us about the nature of spoken word recognition and its underlying mechanisms in that it shows which listener capacities are important and which are not. As such, studying individual differences can "bring us closer to a detailed mechanistic understanding of human language" (Kidd, Donnelly, \& Christiansen, 2018).

Recently, much research attention has been devoted to individual differences in younger and older adults' ability to understand speech in noisy listening conditions, as evidenced by meta-analyses on the association between cognitive performance and speech-in-noise performance (e.g., Dryden, Allen, Henshaw, \& Heinrich, 2017; Füllgrabe \& Rosen, 2016). Both meta-analyses are in line with an earlier literature overview by Akeroyd (2008) in stressing that working memory is the cognitive capacity that has most often been related to the perception of speech masked by noise, particularly for those with hearing impairment (Füllgrabe \& Rosen, 2016). As speech perception can already be challenging in the absence of noise if the speech itself is articulated fast and casually, we investigated if working memory capacity is similarly involved in the recognition of fast speech. While listening in noise may impose challenges because of the incomplete nature of the information, fast speech presents a somewhat different challenge given the fast speed of information delivery. Apart from evidence for working memory capacity as associated with the ability to understand speech in (various) difficult listening conditions, there is also some support for the importance of processing speed (cf. Dryden et al., 2017) or vocabulary knowledge (e.g., Bent, Baese-Bark, Borrie, \& McKee, 2016). By investigating fast-speech perception, we also connect to the discussion whether specific abilities (such as processing speed) may be particularly helpful for certain adverse listening conditions (Bent et al., 2016; Borrie, Baese-Berk, van Engen, \& Bent, 2017; McLaughlin, Baese-Berk, Bent, Borrie, \& van Engen, 2018) or, alternatively, whether listeners may possess a "global speech perception ability" that would be helpful in any kind of adverse listening condition.

In this study, we adopted a multifactor, structural equation modeling approach. We investigated how the four abilities of hearing acuity, working memory, processing speed, and vocabulary are related to the older adults' ability to recognize fast words in acoustically undegraded and degraded conditions. As cognitive and linguistic skills may be interrelated, the use of structural equation modeling (SEM) allows us to investigate which individual (cognitive) capacity is independently associated with target performance, and which only through its association with another (cognitive) capacity. Knowing about unique predictors of spoken-language performance is critical to advance our understanding of the nature of spoken-word recognition. In the remainder of this section, we will elaborate on the importance of these abilities in relation to accounts of the nature of spoken word processing, and on the theoretically inspired question of whether their contribution increases when performance drops to (even) lower levels.

Theoretical models, such as Shortlist B (Norris \& McQueen, 2008), TRACE (McClelland \& Elman, 1986), the Neighborhood Activation Model (Luce \& Pisoni, 1998), and EARSHOT as a more recent model (Magnuson et al., 2020), posit a potential architecture for word recognition, but leave the issue of individual differences underspecified. The models agree on general principles in spoken word recognition, such as the concept of graded activation of multiple word candidates (i.e., 
word representations being activated depending on their similarity to the presented signal) and concepts of competition between word candidates and selection of one best fitting candidate. In principle, word recognition models leave room for individual differences "in the rate at which words accumulate activation, the strength of competition effects, and other factors" (McMurray, Samelson, Lee, \& Tomblin, 2010). A way forward is to identify which sensory, cognitive, or linguistic capacities matter for spoken word recognition, and how these potentially interact with the difficulty of the listening situation. Once identified, we can start to model which capacities are drawn on when.

Several capacities have already been identified. Hearing, as the first capacity to be considered, clearly plays a role in the activation and competition processes required for spoken word recognition, and measures of hearing acuity are routinely included in speech processing studies with older adults (e.g., Humes, 2002, 2007). Hearing acuity determines the quality of the speech signal's auditory representation, which in turn affects activation of word candidates and selection between them (FarrisTrimble, McMurray, Cigrand, \& Tomblin, 2014; McMurray, Farris-Trimble, \& Rigler, 2017). Poor speech audibility due to hearing loss can be problematic particularly for the recognition of fast and reduced speech (e.g., Janse \& Ernestus, 2011; Picheny, Durlach, \& Braida, 1985) because this type of speech is less distinctive than carefully articulated speech.

Second, as mentioned above, there is abundant evidence, both from speech and text processing, that memory capacity is a robust predictor of language processing (see Daneman \& Merikle, 1996 for a review). Furthermore, Akeroyd's literature review of cognitive predictors for speech perception (2008) showed that working memory measures (reading span in particular) were the most consistent cognitive predictors of speech perception performance in noise, which was also the case for recognition of single words (but cf. evidence by Füllgrabe and Rosen (2016) that this association may be stronger for older or poorer hearing populations than for young normal hearing populations). On the basis of general capacity models (Baddeley, 2006; MacDonald, Just, \& Carpenter, 1992; Rönnberg, Rudner, Foo, \& Lunner, 2008), working memory capacity may be involved in spoken word recognition, as resources available for processing (and hence for activation and selection processes) are assumed to be limited. The strain that limited working memory capacity puts on activation and selection processes for spoken word processing should therefore be particularly visible when processing is somehow taxing, as would be the case in adverse listening conditions. For example, in the ease of language understanding (ELU) model, working memory capacity specifically comes into play in adverse listening conditions when speech no longer "automatically" maps onto stored representations (cf. Rönnberg et al., 2008, 2013; Zekveld, Rudner, Johnsrude, Heslenfeld, \& Rönnberg, 2012) and the speech signal can only be interpreted through explicit resource demanding processing. The ELU model, therefore, like other general capacity models, predicts that the role of working memory will be more important as listening conditions become more challenging.

In other working memory models, working memory is more specifically defined as the ability to activate information in long-term memory and to keep it active for ongoing processing (e.g., Cowan, 2005; Ericsson \& Kintsch, 1995; MacDonald \& Christiansen, 2002). These models actually fit quite well with lexical access 
mechanisms as they argue that working memory contains or consists of activated long-term memory information. Working memory capacity may then index an individual's ability to activate (and to keep active) multiple long-term memory representations in order to efficiently resolve the competition process between them (also cf. Sommers, 1996; Sommers \& Danielson, 1999; Taler, Aaron, Steinmetz, \& Pisoni, 2010), rather than capacity for more explicit, task management functions (as in the resource capacity account above). Of importance, in these long-term memory based models (Cowan, 2005; Ericsson \& Kintsch, 1995; Jones, Gobet, \& Pine, 2007; MacDonald \& Christiansen, 2002), working memory capacity is thought to be domain specific and mediated by an individual's expertise or experience. Consequently, working memory capacity would then not also reflect processing resources available for any task at hand but also would more specifically reflect memory for verbal material (as operationalized in verbal working memory measures, such as reading span, digit span, and nonword repetition).

This "verbal expertise" brings us to a third prime candidate that potentially plays a role in facilitating spoken word recognition: vocabulary knowledge. In reading research, the lexical quality hypothesis by Perfetti (1992) holds that a crucial determinant of skilled language processing is the precision of the language user's lexical representations (e.g., Andrews \& Hersch, 2010; Yap, Balota, Sibley, \& Ratcliff, 2012; Yap, Tse, \& Balota, 2009). Yap et al. $(2009,2012)$ suggest that as readers acquire more experience with words, they become increasingly reliant on "automatic lexical processing mechanisms," and less on explicit attention-demanding processing. Reading skill in their work is generally operationalized by vocabulary knowledge, under the assumption that the size of an individual's vocabulary is positively related to the precision (Perfetti, 2007; Perfetti \& Hart, 2002) and stability (Kinoshita, 2006) of the underlying lexical representations. The functional consequence of representations being more precise or fully specified is argued to be that the input will fully determine the representation to be activated, such that a single correct representation is activated with minimal activation of competing candidates. In other words, experience may sharpen lexical representations to "emphasise the features of a word that distinguish it from similar words" (Andrews \& Hersch, 2010).

In speech research, associations have been reported between vocabulary knowledge and the ability to understand noisy speech (McLaughlin et al., 2018; Tamati, Gilbert, \& Pisoni, 2013), periodically interrupted speech (Benard, Mensink, \& Başkent, 2014), foreign-accented speech (Bent et al., 2016; McLaughlin et al., 2018), as well as dysarthric (disordered) speech (McAuliffe, Gibson, Kerr, Anderson, \& LaShell, 2013). McLaughlin et al. (2018), for instance, argue that the association with vocabulary knowledge could be interpreted as either cause or effect of better adverse listening. Greater receptive vocabulary may entail that listeners have stronger lexical mappings, allowing them access to semantic representations even when input is somehow deviant or degraded. Conversely, listeners performing well in adverse conditions may be better able to acquire larger vocabularies "from a variety of talkers and in a variety of situations."

The association between vocabulary knowledge and speech-in-noise performance (for accented as well as unaccented speech) was also investigated by Banks, Gowen, Munro, and Adank (2015), whose path-analysis results provided evidence that vocabulary mediated the relationship between working memory and 
recognition accuracy or accented speech. In other words, vocabulary had a direct, and working memory only an indirect effect, on recognition accuracy. Note that the notion of precision and stability of lexical representation as put forward in the reading literature, as well as the primary role of vocabulary over working memory, as argued for by Banks et al. (2015), is largely similar to the idea of domain-specific working memory.

Furthermore, as a fourth capacity to be considered, we asked whether processing speed plays an independent role in spoken-word processing. Processing speed was not listed as a consistent predictor of speech perception performance in Akeroyd (2008)'s literature review. However, the more recent meta-analysis by Dryden et al. (2017) mentioned a numerically higher correlation coefficient between speech-in-noise performance and processing speed $(r=.39)$ than between speech-in-noise performance and working memory $(r=.28)$. Processing speed may reflect the rate at which words accumulate activation, and may index how quickly individuals can derive information from an unfolding speech signal. In contrast to reading, where the reader can determine the speed of language input, listeners are at the mercy of their interlocutor's speech rate. If processing speed plays an independent role in spoken-word recognition, we may be more likely to find it in the processing of fast speech than in the processing of carefully read aloud speech embedded in noise. In the "working memory as activated long-term memory" models (Cowan, 2005; Ericsson \& Kintsch, 1995; MacDonald \& Christiansen, 2002), processing speed may relate to the ability to quickly access information in long-term memory, and hence to working memory.

\section{The present study}

For each of the four abilities mentioned above, there is evidence that they are related to speech recognition. This study adopted a multifactor, SEM approach to test them in conjunction, to clarify whether hearing acuity, verbal working memory capacity, processing speed, and vocabulary knowledge can independently account for variance in the accuracy with which words taken from fast speech can be recognized, and which only indirectly relate to performance (being mediated by other constructs). As such, SEM provides pointers to which abilities can help us understand spoken-word recognition (for a primer on SEM, the reader is referred to Goodboy \& Kline, 2017).

Older adults were tested as these may be assumed to form a heterogeneous group, both in terms of cognitive abilities and in terms of hearing acuity, and hence in terms of how well they can cope with the input signal. In addition, this study tested speech recognition at two performance levels. This allowed us to address the hypothesis derived from the ease of language understanding model, that working memory would be drawn on more in more adverse conditions. It would also help understand for each of the other variables how or under what conditions speech recognition draws on them. The general prediction is that the association between precursor capacities and spoken word recognition is stronger when listening is more challenging, because (more) adverse listening conditions place greater demands on listeners' capacities to recover the information in the speech signal. The strongest 
evidence for this comes from Heinrich and Knight (2016), who tested correlations between hearing acuity and speech-in-noise performance at two different recognition levels by manipulating signal-to-noise ratio, and found that the association with hearing acuity was stronger at the poorer recognition level.

The speech fragments for the word recognition task were taken from conversational or fast fragments. This speech is more difficult to process than clear speech, as the information presented is often less distinctive (or "acoustically reduced," implying segments missing and vowel or consonant contrasts not being fully realized) and is presented in less time (Ernestus, Baayen, \& Schreuder, 2002; Janse, 2004; Janse, Nooteboom, \& Quené, 2007; Ranbom \& Connine, 2007; Tucker, 2011; van Engen, Chandrasekaran, \& Smiljanic, 2012; Koch \& Janse, 2016). As mentioned above, we also investigated whether the strength of the association between the precursor capacities and speech recognition performance changes when word recognition is made more challenging. To this end, speech audibility of the fast words was manipulated by low-pass filtering the acoustic signal. This type of filtering presents a rough estimation of high-frequency hearing loss (age-related hearing loss typically affecting the high-frequency part of the speech spectrum most), such that we can simulate dampening of high-frequency spectral information even in participants with better hearing. The same type of low-pass filtering degradation brought younger adults to the same speech recognition level as older adults in a study in which reduced words and fragments taken from conversational speech were presented (Janse \& Ernestus, 2011). Inclusion of this filtering manipulation in the present study thus enabled us to investigate the contribution of speech audibility to fast-word recognition from two angles: by looking at continuous variation in high-frequency hearing loss in our participant sample of older adults who are not wearing hearing aids and by low-pass filtering the signal.

\section{Method}

\section{Participants}

A total of 105 participants were tested in this study (36 male and 69 female). All of them were native speakers of Dutch, living independently in the Nijmegen area. They were all over 60 years of age. They were recruited from the Max Planck Institute participant pool and were paid for their participation ( $€ 8$ per hour). They did not report any neurological damage and did not wear hearing aids in their daily life. No other criteria were set with respect to participants' hearing ability. Mean age was 68.26 years $(S D=6.06$, range $=60-83$ years $)$.

\section{Tasks and materials}

Hearing acuity

Air-conduction hearing thresholds were assessed with an Oscilla USB-300 screening audiometer in a sound-attenuating booth. Mean thresholds are given in Figure 1 for octave frequencies from 0.25 to $8 \mathrm{kHz}$ for both the left and right ear. A high-frequency pure-tone average (HFPTA) was calculated for each participant's better ear over 1,2 , and $4 \mathrm{kHz}$ as an index of high-frequency hearing loss (higher values indicating poorer hearing). Mean HFPTA was $23.44 \mathrm{~dB} \mathrm{HL}$ $(S D=10.79$, range $=5-51.67)$. 


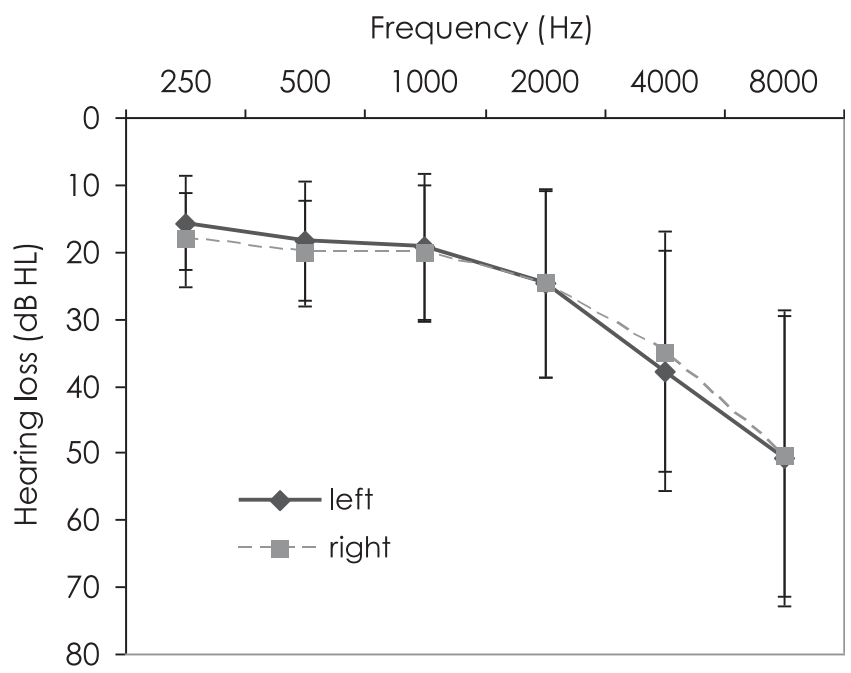

Figure 1. Mean hearing thresholds ( $\mathrm{dB} \mathrm{HL}$ ) for both ears at octave frequencies from 250 through $8000 \mathrm{~Hz}$. Error bars indicate one standard deviation.

\section{Working memory}

Backward digit span. A computerized version of the backward digit span task (a subpart of the Wechsler Adult Intelligence Test; Wechsler, 2004) was used to measure individual working memory capacity (E-Prime v1.2 software was used; Schneider, Eschman, \& Zuccolotti, 2002). In this task, a series of digits appeared sequentially in the center of the computer screen for $1 \mathrm{~s}$. The interval between consecutive digits was $1 \mathrm{~s}$. Digits were presented in a large white font (Arial, font size 100) against a black background. After the presentation of a digit sequence (e.g., 362 ), participants were prompted to recall the digits in reversed order (e.g., 263 ) by typing them in on the computer keyboard. Participants first practiced with two three-digit trials, before being tested twice on sequences including 2 to 7 digits (i.e., 12 trials in total). Trials were the same for all participants regardless of their performance. Individual performance on this task was determined as the proportion of correctly recalled digit sequences out of 12 test trials, regardless of digit sequence length. Larger proportions thus indicated better working memory. Mean proportion correct in this task was $0.47(S D=0.18)$.

Auditory short-term memory. An auditory nonword repetition task was used as an index of verbal/phonological short-term memory (Gathercole \& Baddeley, 1996; Thorn \& Gathercole, 1999). Researchers have also referred to it as an index of phonological storage (e.g., Gathercole, 2006), phonological buffer capacity (Bates, Luciano, Montgomery, Wright, \& Martin, 2011), or phonological working memory (Gathercole, Willis, Baddeley, \& Emslie, 1994; McGettigan et al., 2011). The task has been widely used in research on developmental dyslexia (e.g., Ramus \& Szenkovits, 2008). The task consisted of the presentation of 50 nonwords, all of which were phonotactically legal in Dutch (de Jong \& van der Leij, 1999). The speaker was a professional speech therapist and female native speaker of Dutch who spoke at a 
consistently slow and clear speaking rate. The nonword items were presented over headphones at a fixed mean intensity level of $80 \mathrm{~dB}$ SPL (E-Prime software v1.2 was used for computerized presentation). Participants were seated in a soundattenuating booth. Each nonword was presented only once, after which participants were asked to repeat the nonword. Intertrial time was $3 \mathrm{~s}$. Nonwords of different syllable lengths (two to five syllables long) were presented intermixed, but the order in which they were presented was kept constant for all participants. Responses were recorded to allow for offline scoring. Transcription and scoring was done by a native speaker of Dutch. If all syllables of a particular item were reproduced correctly, a score of 1 was obtained. If not all syllables were repeated correctly, a proportion correct was computed (number of correctly repeated syllables divided by total syllable number for that target nonword). Maximum score for the entire task was thus in principle 50 (for 50 correctly repeated nonword items). Mean score for this task was $35.82(S D=7.06)$. Higher scores reflected better auditory verbal short-term memory. As hearing sensitivity significantly correlates with performance on this auditory task $(r=-.64, p<.001)$, individual task scores were corrected for hearing sensitivity differences by replacing them with the residuals of a linear regression model predicting nonword repetition performance as a function of hearing sensitivity.

Reading span. A computerized standard version of a reading span test was used with Dutch-language materials (van den Noort, Bosch, Haverkort, \& Hugdahl, 2008). The test was programmed in E-Prime v1.2. The test has five different versions of which two (Series 1 and 2) were administered to our participants. The participants' task was to read each sentence aloud. When participants had finished reading a sentence, they pressed the space bar, after which another sentence appeared on the screen. If the participant could not finish the sentence within $8 \mathrm{~s}$, the computer automatically presented the next sentence. When a participant had completed all the sentences of a set, the word "recall" was presented. At that point, participants had to recall the last word of each sentence in the set. The order of recall was free. When done recalling, the participant could either press the space bar or wait for the time-out of $15 \mathrm{~s}$, after which the program would proceed with the next set (note that this reading span task does not involve semantic anomaly judgments as in some papers, e.g., in Rudner, Rönnberg, \& Lunner, 2011; Zekveld et al., 2011).

As in the original reading span test (Daneman \& Carpenter, 1980), the sentences within each series were presented in different set sizes $(2,3,4,5$, or 6 sentences), such that participants could not anticipate when the "recall" sign would appear. The total number of correctly remembered words was determined. Each series consisted of 20 sentences, such that in principle maximum score of correctly remembered words is 40 . Mean total number of remembered words was $24.24(S D=5.36)$.

\section{Information processing speed}

Digit-symbol substitution performance. Participants completed the paper-and-pencil Digit Symbol substitution test, which measures the time needed to recode a number of digits to symbols (cf. also Deary, Johnson, \& Starr, 2010; Hoyer, Stawski, Wasylyshyn, \& Verhaeghen, 2004, Lemke \& Zimprich, 2005). This test is part of the Wechsler Adult Intelligence Scale Test (Wechsler, 2004). Participants were given 
$90 \mathrm{~s}$ in which they should try and substitute as many digits for symbols (given a key at the top of the page). The mean number of correct substitutions was 48.2 $(S D=10.66)$, such that mean time needed to code a digit into a symbol was $2.12 \mathrm{~s}(S D=0.62)$. The latter value (in milliseconds) was entered as a variable for information processing speed, such that lower numbers reflect faster processing.

Letter comparison. In this task, participants were presented with two letter strings (all consonants) on the computer screen: one centered in the top half of the screen and one string centered in the lower half. As in the other computerized experiments, E-Prime software v1.2 was used. Participants were instructed to decide as quickly as possible whether the two letter strings were the same or different by pressing buttons on a response button box labeled "same" or "different" (see Earles \& Salthouse, 1995; Salthouse, 1996 for a paper-and-pencil version of this task as a speed measure). In the first experimental block, letter strings of both strings to be compared were made up of three letters (e.g., TZF). In the second block, six letter strings (e.g., RNHKTG) were presented. Letters were presented in a large black font (Arial 60) against a white background. If the strings were different, they would only differ in one letter in any of the three (for the three-letter strings) or six (for the six-letter strings) positions. Within each block, 12 trials contained identical strings and 12 trials contained different strings, making up 48 trials in total. In order to familiarize participants with the task, participants were first presented with six practice trials. If the procedure was clear, they would proceed to the test phase. Each trial would start with the presentation of a fixation cross, which stayed on the computer screen for $500 \mathrm{~ms}$. After another $100 \mathrm{~ms}$, the two letter strings would be presented. These letter strings would stay on the screen until the participant responded. The next trial would be presented after an intertrial time of $1000 \mathrm{~ms}$. Mean accuracy proportion over the 48 test trials was $0.97(S D=0.03)$. For all correct responses, an RT cutoff criterion of $3 S D$ above the overall mean was calculated. This led to exclusion of $1.2 \%$ of the data points. On the basis of this data set (incorrect and extremely slow responses excluded), each participant's mean RT was calculated and was entered as individual speed. Mean letter comparison RT was $1842 \mathrm{~ms}(S D=387)$. As in the digit-symbol substitution task, lower values reflect faster processing speed.

Vocabulary knowledge. A 60-item receptive multiple-choice test was used to assess vocabulary size (Andringa, Olsthoorn, van Beuningen, Schoonen, \& Hulstijn, 2012). The test by Andringa et al. (2012) consists of a selection of items from Hazenberg and Hulstijn's (1996) test for second-language speakers of Dutch and new items that make the test suitable for native speakers. Target words were presented on a computer screen (Courier, font size 15) in neutral carrier sentences (e.g., the target word mentaliteit ["mentality"] was presented in the carrier phrase "Wat een vreemde mentaliteit!" ["What a strange mentality!"]). Participants were asked to choose the best description of the word's meaning out of five alternatives (e.g., for "mentality": 1. Table; 2. Person; 3. Way of thinking; 4. Atmosphere; or 5. I really don't know). The last option was always "I really don't know." Individual scores were defined as the number of correct items (out of 60). Higher scores indicated better vocabulary knowledge. The mean number of correct items was $52.19(S D=4.08)$. For the sake of the analyses, the vocabulary items were randomly divided over three subsets consisting of 20 items each. 


\section{Word recognition}

Stimuli creation. Words to be presented as target stimuli for the present study were taken from Dutch sentences also used and described in Adank and Janse (2009). The sentences were translations from sentence material in the Speed and Capacity of Language Processing Test (Baddeley et al., 1992). In this test, which can be administered in a written or auditory form, the participant has to decide as accurately and as quickly as possible whether sentence statements are true or false (e.g., for a true sentence: People wear socks on their feet; and for a false sentence: Most cars run on apple juice). There were 180 sentences in total (90 true and 90 false statements).

The speaker was a 31-year-old male speaker of Standard Dutch who had lived in the Netherlands all his life. The true and false sentences were presented for the speaker to read on a computer screen. He was asked to read the sentences as declarative statements. The speaker had already produced all sentences at his normal rate before producing them at a fast rate. For the fast-rate recording, he was instructed to always first read the sentence silently, and to then pronounce each sentence four times in a row. This turned out to be the most efficient way to produce the sentences quickly, fluently, and accurately. The fast and acoustically reduced speech style that the speaker produced through this elicitation procedure will be referred to as fast. The recordings were made in a sound-treated room, using a Sennheiser ME64 microphone. The recordings were saved as separate sentence files and downsampled to $22050 \mathrm{~Hz}$ (to limit file loading time). Out of the four attempts to produce each sentence, the second sentence was selected in the majority of the cases. As noted in Adank and Janse (2009), mean speech rate of these fast sentences was 10.2 intended syllables/s ( $S D=1.6$ syllables/s) and young listeners' sentence verification accuracy on these fast sentences was significantly poorer than on the normal-rate sentences ( $82 \%$ in the fast condition [chance level being 50\%], versus $97 \%$ in the normal-rate condition, which had a mean speech rate of 4.7 syllables/s).

Out of the 180 sentences, 100 noun words were excised as stimuli for the present study and were stored as separate audio files. The stimuli were faded in and out with a 10-ms raised cosine window to avoid too abrupt sound onsets and offsets (all speech signal editing was done in Praat, available from www.praat.org). The nouns were taken from sentence-initial, sentence-medial and sentence-final positions. Due to the fast speaking style, some extracted items may have contained coarticulatory information about segments from preceding or following words. Nouns were one to four syllables long. Several nouns were in plural form (e.g., stoelen "chairs," ooms "uncles," and vleugels "wings"). Word frequencies (per million words) for these nouns were extracted from the SUBTLEX-NL corpus (Keuleers, Brysbaert, \& New, 2010). Mean log word frequency of the items was $2.63(S D=0.89)$.

Stimuli were low-pass filtered with a sloping filter with a $20 \mathrm{~dB} /$ octave rolloff from $1 \mathrm{kHz}$ onward. This filtering manipulation hardly affected the mean intensity of the stimuli (intensity difference between conditions being smaller than $1 \mathrm{~dB}$ ).

Each participant was presented with 100 items in total, half unfiltered and half filtered. The items were divided over two stimulus lists according to a Latin-square design. Items that were filtered in stimulus list one were unfiltered in stimulus list two and vice versa. For the sake of the statistical analyses, the stimulus lists were further divided into subsets (or parcels) of 25 items (UnfilteredSetA, UnfilteredSetB, FilteredSetA, and FilteredSetB). Thus, on one list, the same set of 25 items makes up UnfilteredSetA, whereas it makes up FilteredSetA on the other list. 
In order to have intelligibility reference data for the words in the two listening conditions, we presented the stimuli to a small sample of young normal-hearing adults $(N=14$, all native speakers of Dutch aged between 19 and 24 and students at Radboud university), following the same task procedure as outlined below. Pure-tone thresholds in the young participants' better ear (at octave frequencies from $0.25 \mathrm{kHz}$ to $8 \mathrm{kHz}$ ) did not exceed $15 \mathrm{~dB}$ HL. Mean accuracy in the unfiltered condition was $70 \%(S D=5.89)$, and mean accuracy in the filtered condition was $56 \%(S D=10.88)$. These data show that intelligibility of the fast words, even in the unfiltered condition, was not at ceiling for a young normal-hearing listener group either.

Task procedure. Participants were told that they would be presented with words taken from fast speech and that they would have to identify the words. The experiment was run using E-Prime software v1.2. Each trial started with a large black fixation cross, against a white background, which stayed in the center of the screen for $500 \mathrm{~ms}$. The fixation cross was followed by a $200 \mathrm{~ms}$ blank screen, after which the auditory stimulus was presented. Participants were presented with the stimuli over closed headphones (Sennheiser HD 215) in a sound-attenuated booth at an average presentation level of $80 \mathrm{~dB}$ SPL (each unfiltered stimulus had been set to the same mean intensity level and the filtering manipulation had hardly affected mean intensity). All words were presented diotically. Items in the unfiltered and low-pass filtered conditions were presented intermixed as the order of items on the list was randomized for each participant. They were encouraged to guess which word had been presented if the word was unintelligible and to type in their responses using a regular computer keyboard. Whenever participants were not comfortable using a keyboard, the student assistant would type in the responses for them. After the participant had pressed the Enter key, the next trial would start (with the $500 \mathrm{~ms}$ fixation cross). Prior to the start of the test phase, 12 practice items were presented to familiarize participants with the talker and the task. The listening task took approximately $15 \mathrm{~min}$.

All responses to the speech stimuli were scored by a human rater as being correct (coded as 1 ) or incorrect (coded as 0 ). Whenever a plural ending was added or omitted, this was scored as correct. The rater also gave full credit whenever there were obvious typos (e.g., sinmasappel for sinaasappel "orange"). Mean accuracy in the unfiltered condition was $52 \%(S D=15$, range: $12 \%-82 \%)$, and mean accuracy in the low-pass filtered condition was $25 \%(S D=13$, range: $4 \%-62 \%)$. Broken down by item set, mean performance accuracy was $51 \%(S D=15)$ for UnfilteredSetA, 53\% $(S D=17)$ for UnfilteredSetB, $24 \%(S D=13)$ for FilteredSetA, and 26\% $(S D=15)$ for FilteredSetB. There were no violations of normality in these accuracy distributions, such as skewness of kurtosis. Accuracy performance is also given in Figure 2.

Participants were first presented with the listening task (which took about $15 \mathrm{~min}$ ) and then with the other tasks (test of hearing acuity [10 $\mathrm{min}$ ], digitsymbol substitution task [2 $\mathrm{min}$ ], nonword repetition [10 $\mathrm{min}$ ], digit span task [5 $\mathrm{min}$ ], letter comparison [8 $\mathrm{min}$ ], vocabulary task [15 $\mathrm{min}$ ], and reading span [10 min]). The total session, including small breaks between tests, lasted about an hour and a half. 


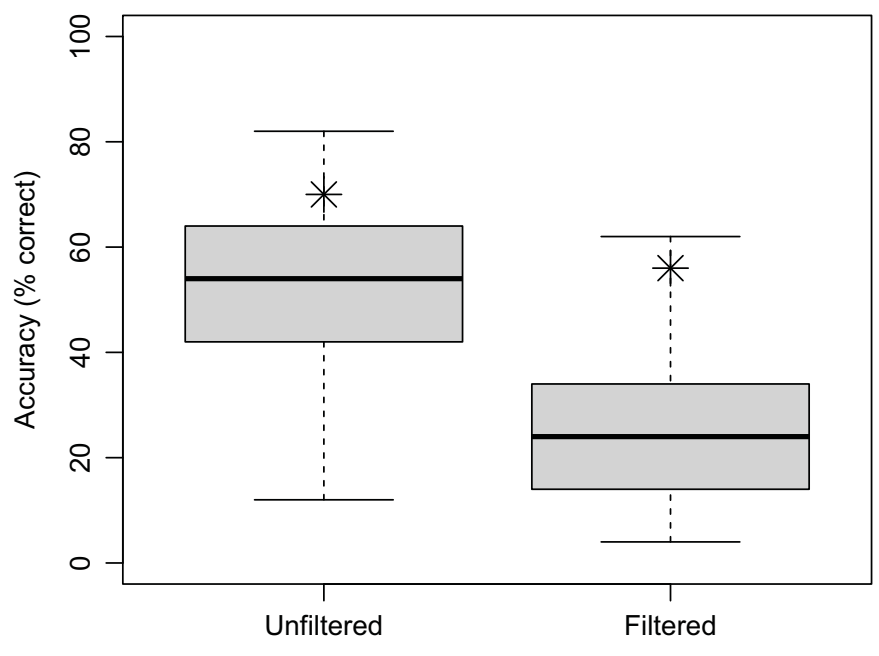

Condition

Figure 2. Boxplot of accuracy performance in the two listening conditions. Asterisks indicate mean word recognition accuracy of a young normal-hearing reference group.

\section{Analyses}

SEM was used to model the relationship between word recognition accuracy and the hypothesized predictors (see Goodboy \& Kline, 2017, for an introduction to SEM). SEM combines confirmatory factor analysis and correlation and regression, and distinguishes measurement models from structural models. At the level of measurement, the goal was to assess how well the measures described above are indicators of word recognition accuracy, hearing sensitivity, working memory, processing speed, and receptive vocabulary knowledge. At the structural level, the goal was to model how well hearing sensitivity, working memory, processing speed, and vocabulary predict individual differences in word recognition in unfiltered and low-pass filtered speech. The advantage of SEM is that it assesses the predictive value of each of the extracted factors while taking into account how these factors are themselves interrelated.

The factors that result from confirmatory factor analysis consist of the variance that each of its indicators (the observed variables) has in common. As a result, measurement error in the observed variables is partialed out and the latent variables may be considered free of measurement error. Because latent variables are preferably indicated by several observed variables, the items of the vocabulary test and the word recognition task were divided randomly into subsets or parcels (as described above), but parcels always consisted of at least 20 items. For hearing sensitivity, working memory, and processing speed no parceling was needed as we had several indicators for each.

SEM involves testing how well the observed data conform to the hypothesized model. Several indices of model fit exist. In this paper, we assessed the $\chi^{2}$ test, which is sensitive to sample size and model complexity, but is useful in comparing nested models. In addition, the $\chi^{2} / d f$ ratio was used, which should be smaller than $<2$. In 
addition, we made use of two indices that make adjustments for sample size and model complexity: the comparative fit index (CFI), which is preferably larger than 0.95 , and the root mean squared error of approximation (RMSEA), which should be smaller than 0.06 (cf. Hu \& Bentler, 1999).

A step-wise approach was adopted in modeling the data. Before we evaluated any relationships at the structural level of the model, we first assessed the appropriateness of the measurement model. At the measurement level, separate analyses were conducted for word recognition and hearing acuity. For word recognition, the goal was to test the assumption that two separate factors can be distinguished for recognition in unfiltered versus low-pass filtered conditions. For hearing acuity, we implemented a model of hearing loss as presented in Rönnberg et al. (2011) based on better ear pure-tone thresholds of $0.5,1,2$, and $4 \mathrm{kHz}$. Finally, the remaining variables, which were intended as indicators of working memory, processing speed, and vocabulary knowledge, were analyzed together in one model. In addition, not only the fit of the hypothesized model was evaluated, but also those of plausible alternative models. This was done either to confirm the appropriateness of the hypothesized model or to select the solution that fitted our data best, and is a generally recommended procedure (Goodboy \& Kline, 2017; Kline, 2005).

As a final step, we modeled the structural relationships. As all predictors were hypothesised to explain variance in word recognition accuracy, a full model was constructed first containing all possible relationships. The most parsimonious model was then selected by means of a backward deletion process. In this exploratory procedure, regression weights that were not found to be significantly different from zero were set to zero, effectively removing them from the model. This was done only if their removal did not lead to significant loss of model fit in $\chi^{2}$ points compared to the loss of degrees of freedom. At each step in the process, the quality of the data was assessed by inspecting univariate and multivariate normality on the basis of skewness, kurtosis and the Mahalanobis distance estimates. The values for skewness and kurtosis should lie below the maximum values considered acceptable for SEM analyses, that is, 3 for skewness and 10 for kurtosis (Kline, 2005). Violations of univariate or multivariate normality were never observed in the analyses to be presented below. Note that outliers were not removed in any of the measures (apart from response time outliers in the Letter Comparison task, see description). There were no missing data.

\section{Results}

\section{The measurement model}

Table 1 presents the correlations between the observed variables before any parceling took place. For this purpose, hearing acuity was determined by calculating a high-frequency pure-tone average (HFPTA) over 1, 2, and $4 \mathrm{kHz}$ for each individual's better ear. The table shows that each of the independent variables correlated with either word recognition in unfiltered speech or with recognition in low-pass filtered speech, or with both. It also shows that correlations between the predictors were generally weak, with the exception of the two measures of processing speed, which correlated moderately (.53). 
Table 1. Pearson correlations for all observed variables (only significant correlations are given at $\alpha<.05$, 2-tailed $\mathrm{N}=105$ ); the numbers in the top row correspond to the numbers in the first column

\begin{tabular}{|c|c|c|c|c|c|c|c|c|c|}
\hline Variable & 1 & 2 & 3 & 4 & 5 & 6 & 7 & 8 & 9 \\
\hline 1. Word recognition acc. unfiltered & 1 & & & & & & & & \\
\hline 2. Word recognition acc. filtered & .70 & 1 & & & & & & & \\
\hline 3. Hearing acuity & -.50 & -.56 & 1 & & & & & & \\
\hline $\begin{array}{l}\text { 4. Nonword repetition task } \\
\text { (residual) }\end{array}$ & .43 & .25 & & 1 & & & & & \\
\hline 5. Digit span task & .22 & .23 & & & 1 & & & & \\
\hline 6. Reading span task & .24 & & & .27 & .26 & 1 & & & \\
\hline 7. Digit-symbol substitution task & -.33 & -.31 & .34 & & -.24 & -.33 & 1 & & \\
\hline 8. Letter-string comparison task & & -.24 & .23 & & & -.36 & .53 & 1 & \\
\hline 9. Vocabulary knowledge & & .22 & & .27 & .24 & .37 & -.31 & -.25 & 1 \\
\hline
\end{tabular}

As a first step in the analysis, we assessed the appropriateness of extracting two factors from the Word Recognition task: recognition of unfiltered words versus recognition of low-pass filtered words. To this end, we compared two models. The first consisted of two latent variables that were each regressed onto two parcels based on the unfiltered speech items (unfiltered) and two parcels based on the low-pass filtered items (filtered). The second model consisted of one latent variable regressed onto all four parcels. The two-factor solution yielded good model fit: $\chi^{2}(1)=0.41$, $p=.84, \chi^{2} / d f$ ratio $=0.41, \mathrm{CFI}=1.000$, and RMSEA $=0.00$. The one-factor model fitted poorly: $\chi^{2}(2)=28.10, p=.00, \chi^{2} / d f$ ratio $=14.05, \mathrm{CFI}=0.898$, and RMSEA $=0.354$. Clearly, the solution that distinguishes between the factors unfiltered and filtered is to be preferred over a model that makes no allowance for the two types of listening conditions. Table 2 summarizes this model. All factor loadings are above 0.80 . UnfilteredSetB has the largest error variance associated with it, but a respectable amount of $65 \%$ of its variance is still explained by the model, as indicated by the squared multiple correlation.

Second, hearing acuity was modeled, following Rönnberg et al. (2011), on the basis of the observed hearing threshold values at $0.5,1,2$, and $4 \mathrm{kHz}$ in the better ear (cf. Lin, Thorpe, Gordon-Salant, \& Ferrucci, 2011, who refer to this frequency range as being most relevant for speech). The model consisted of one better ear hearing acuity factor regressed onto the four pure-tone threshold scores. If the residual variances at $0.5 \mathrm{kHz}$ and $1 \mathrm{kHz}$ were allowed to covary, the model fitted reasonably well: $\chi^{2}(1)=2.31, p=.13, \chi^{2} / d f$ ratio $=2.31, \mathrm{CFI}=0.991$, and RMSEA $=0.112$. The results are displayed in Table 3.

Third and finally, we tested whether the measures of nonword repetition, digit span, reading span, digit-symbol substitution, letter string comparison, and vocabulary (parceled into three subsets) were accurate representatives of working memory, processing speed, and vocabulary knowledge. Again, two alternative models were tested. First, a three-factor model was tested that conformed to the hypothesized underlying structure: a working memory factor was regressed onto the reading span, 
Table 2. Model solution for word recognition accuracy, presenting standardized $(\beta)$ and unstandardized (B) factor loadings, standard errors (SE), squared multiple correlations (SMC), and error variance estimates

\begin{tabular}{lllccc}
\hline Observed variable & Latent construct & $\beta$ & $\mathrm{B}(\mathrm{SE})$ & $\mathrm{SMC}$ & Error var. (SE) \\
\hline UnfilteredSetA & Unfiltered & .94 & $0.138(0.012)^{\star}$ & .88 & $.003(.002)$ \\
\hline UnfilteredSetB & Unfiltered & .81 & $0.139(0.015)^{\star}$ & .65 & $.010(.002)^{\star}$ \\
\hline FilteredSetA & Filtered & .87 & $0.108(0.010)^{\star}$ & .75 & $.004(.001)^{\star}$ \\
\hline FilteredSetB & Filtered & .91 & $0.137(0.012)^{\star}$ & .82 & $.004(.001)^{\star}$ \\
\hline Covariances & & \multicolumn{7}{c}{ Correlation } & Estimate $(S E)$ \\
\hline Unfiltered-Filtered & & & .80 & $.80(.05)^{\star}$ \\
\hline
\end{tabular}

${ }^{\star}$ Differs significantly from zero $(p<.05)$.

Table 3. Model solution for hearing acuity based on better ear threshold values, presenting standardized $(\beta)$ and unstandardized (B) factor loadings, standard errors (SE), squared multiple correlations (SMC), and error variance estimates

\begin{tabular}{llcccc}
\hline Observed variable & Latent construct & $\beta$ & $B(S E)$ & $S M C$ & Error var. (SE) \\
\hline $0.5 \mathrm{kHz}$ & Hearing acuity & .27 & $1.00^{\mathrm{a}}$ & .07 & $54.65(7.73)^{\star}$ \\
\hline $1 \mathrm{kHz}$ & Hearing acuity & .63 & $2.89(.96)^{*}$ & .65 & $53.54(8.74)^{\star}$ \\
\hline $2 \mathrm{kHz}$ & Hearing acuity & .83 & $5.38(2.17)^{\star}$ & .69 & $57.21(17.49)^{*}$ \\
\hline $4 \mathrm{kHz}$ & Hearing acuity & .81 & $7.28(2.94)^{*}$ & .40 & $121.56(33.07)^{*}$ \\
\hline $\begin{array}{l}\text { Error covari- } \\
\text { ance }\end{array}$ & & & Correlation & & Covariance (SE) \\
\hline $0.5 \mathrm{kHz}-1 \mathrm{kHz}$ & & .58 & & $31.14(6.70)^{*}$ \\
\hline
\end{tabular}

a Set to 1 to achieve model identification. ${ }^{\star}$ Differs significantly from zero $(p<.05)$.

digit span, and residualized nonword repetition scores; a processing speed factor was regressed onto the digit-symbol substitution and letter comparison scores; and a vocabulary knowledge factor was regressed onto the three vocabulary subset scores. This model achieved good fit: $\chi^{2}(6)=1.697, p=.89, \chi^{2} / d f$ ratio $=0.34, \mathrm{CFI}=1.000$, and RMSEA $=0.000$. We considered a two-factor model that did not make a distinction between working memory and processing speed to be the most plausible alternative. Here one cognitive ability factor was regressed onto the five memory and speed measures. This model did not meet the criteria for good model fit on the CFI and RMSEA indices: $\chi^{2}(19)=30.363, p=.05, \chi^{2} / d f$ ratio $=1.60, \mathrm{CFI}=0.937$, and RMSEA $=0.076$. The three-factor solution was retained and its details are presented in Table 4. As can be seen, the two processing speed variables and the vocabulary subscores were good indicators of their respective latent variables. For working memory, however, we found that reading span was by far the most important contributor. The squared multiple correlations for nonword repetition and digit span performance show that no more than $13 \%$ and $15 \%$ of their variance was explained by the model. 
Table 4. Model solution for memory, processing speed and vocabulary knowledge, presenting standardized ( $\beta$ ) and unstandardized (B) factor loadings, standard errors (SE), squared multiple correlations (SMC), and error variance estimates

\begin{tabular}{|c|c|c|c|c|c|}
\hline Observed variable & Latent construct & $\beta$ & $B(S E)$ & SMC & Error var. (SE) \\
\hline Nonword rep. & Working memory & .36 & $1.95(0.63)^{\star}$ & .13 & $25.09(3.67)^{\star}$ \\
\hline Digit span & Working memory & .39 & $6.97(2.08)^{\star}$ & .15 & $270.59(41.24)^{\star}$ \\
\hline Reading span & Working memory & .72 & $3.82(0.70)^{\star}$ & .51 & $13.82(4.56)^{*}$ \\
\hline Digit-symbol task & Processing speed & .74 & $351.9(58.6)^{\star}$ & .51 & $104177(33419)^{*}$ \\
\hline Letter comparison task & Processing speed & .71 & $274.9(46.7)^{\star}$ & .54 & $72944(20989)^{\star}$ \\
\hline VocabSetA & Vocabulary know. & .67 & $0.059(0.008)^{\star}$ & .45 & $0.004(.001)^{\star}$ \\
\hline VocabSetB & Vocabulary know. & .75 & $0.056(0.007)^{\star}$ & .58 & $0.002(.001)^{\star}$ \\
\hline VocabSetC & Vocabulary know. & .83 & $0.071(0.008)^{\star}$ & .69 & $0002(.001)^{\star}$ \\
\hline Covariance & & & \multicolumn{2}{|c|}{ Correlation } & Estimate (SE) \\
\hline \multicolumn{3}{|c|}{ Working memory-Processing speed } & \multicolumn{2}{|c|}{-.60} & $-.60(.14)^{\star}$ \\
\hline \multicolumn{3}{|c|}{ Working memory-Vocabulary know. } & \multicolumn{2}{|c|}{.60} & $.60(.12)^{\star}$ \\
\hline \multicolumn{3}{|c|}{ Processing speed-Vocabulary know. } & \multicolumn{2}{|c|}{-.42} & $-.42(.12)^{\star}$ \\
\hline
\end{tabular}

${ }^{*}$ Differs significantly from zero $(p<.05)$

\section{The structural model}

The results obtained in the analyses at measurement level were subsequently used to model the hypothesized relationships between word recognition in both unfiltered and filtered fast speech on the one hand, and hearing acuity, working memory capacity, processing speed, and vocabulary knowledge on the other. One can think of our data as repeated measures data, where word recognition accuracy was measured in both unfiltered and filtered conditions. Repeated measures data are often analyzed by means of analyses of covariance, where the effect of a particular treatment on a posttest is predicted from pretest results in addition to the treatment. These data were modeled in a similar fashion: All four predictors (hearing acuity, memory capacity, processing speed, and vocabulary knowledge) were regressed onto both word recognition factors (unfiltered and filtered). However, we also regressed the unfiltered speech factor onto the filtered speech factor. In setting up our model this way, we tested (a) which of the four independent factors predicted word recognition ability in unfiltered speech and (b) which of the four independent factors predicted word recognition ability in low-pass filtered speech on top of what is already explained by word recognition in unfiltered speech. The model is graphically depicted in Figure 3. It met all criteria for good model fit: $\chi^{2}(88)=109.17, p=.06, \chi^{2} / d f$ ratio $=1.24, \mathrm{CFI}=0.968$, and RMSEA $=0.0484$. As a final step, the most parsimonious model was selected. Five out of nine structural regression weights were found not to differ significantly from zero and were set to zero (see Figure 4). The loss of model of fit associated with their removal was not significant: $\Delta \chi^{2}(5)=6.3205 .231, p=.28$.

Table 5 and Figure 4 display the final model results. A similar pattern of correlations was found for the predictors with unfiltered and filtered word recognition 


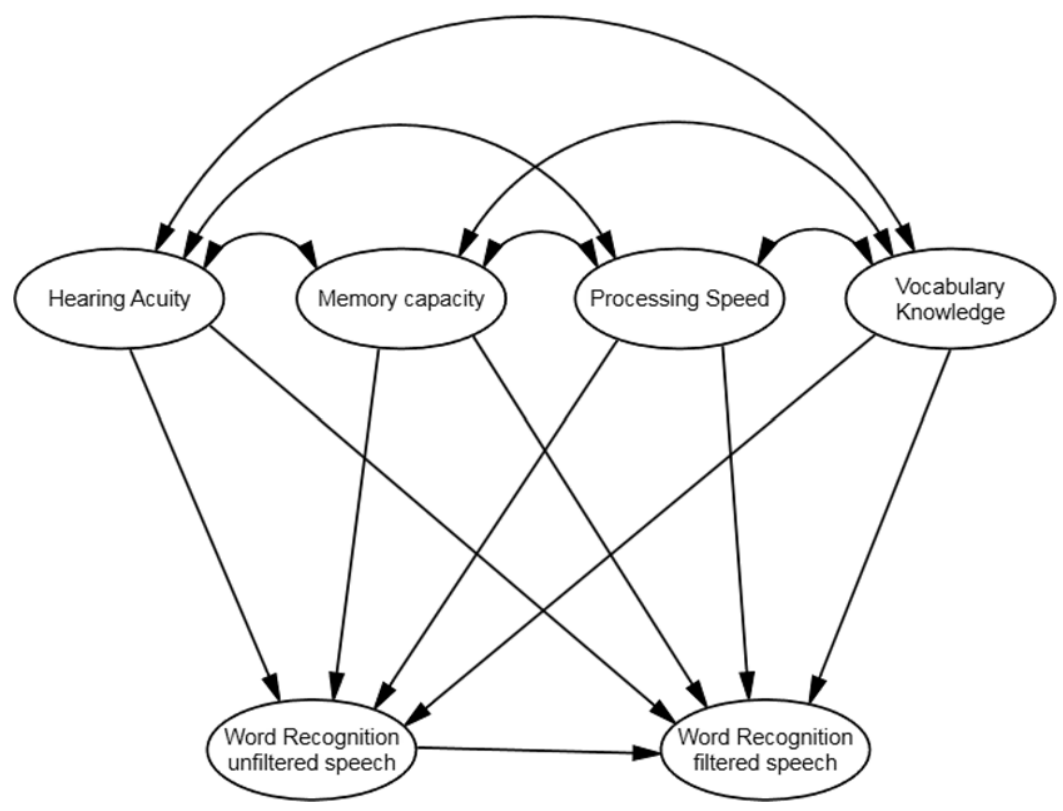

Figure 3. Tested structural model of word recognition in the two listening conditions.

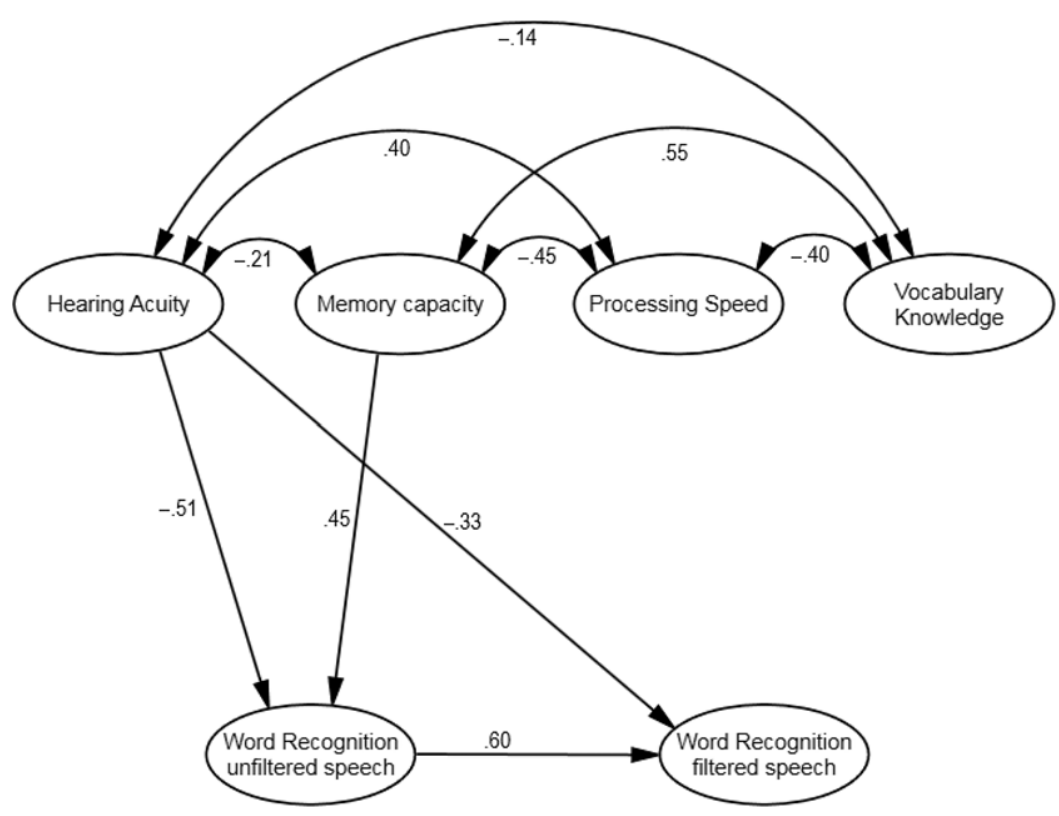

Figure 4. Observed standardised regression weights of the latent factors with Word Recognition Accuracy in filtered and unfiltered speech conditions. 
Table 5. Implied correlations and standardized regression weights of the latent factors with the dependent variable word recognition accuracy as obtained in the final model

\begin{tabular}{|c|c|c|c|c|}
\hline \multirow[b]{2}{*}{ Predictors } & \multicolumn{2}{|c|}{$\begin{array}{l}\text { Word recognition } \\
\text { unfiltered }\end{array}$} & \multicolumn{2}{|c|}{$\begin{array}{c}\text { Word recognition fil- } \\
\text { tered }\end{array}$} \\
\hline & $r$ & $\beta$ & $r$ & $\beta$ \\
\hline Hearing acuity & -.60 & -.51 & -.69 & -.33 \\
\hline Working memory & .56 & .45 & .40 & - \\
\hline Processing speed & -.41 & - & -.37 & - \\
\hline Vocabulary knowledge & .32 & - & .24 & - \\
\hline Word recognition unfiltered & n.a. & n.a. & .80 & .60 \\
\hline Variance explained & \multicolumn{2}{|c|}{$55 \%$} & \multicolumn{2}{|c|}{$70 \%$} \\
\hline
\end{tabular}

accuracy: the strongest correlation was found for hearing acuity, the weakest for vocabulary. All correlations were in the expected direction: participants tended to perform better on the word recognition task as they experienced less hearing difficulties, as their working memory capacity was larger, as their processing speed was faster, and as their vocabulary knowledge was larger. The standardized regression weights show that neither processing speed nor vocabulary knowledge explained any unique variance in unfiltered or filtered word recognition accuracy. In total, 55\% of the variance in unfiltered word recognition accuracy was explained by hearing acuity and working memory, the former accounting for a slightly larger share of the variance than the latter. In filtered word recognition accuracy, a total of $70 \%$ of the variance was explained. However, the vast majority of that variance was explained by word recognition accuracy in unfiltered speech. Hearing acuity explained a significant amount of extra variance. This latter finding should be interpreted as an interaction between hearing acuity and type of word recognition, such that hearing acuity was significantly more predictive of individual differences in filtered than in unfiltered word recognition. None of the other predictors were found to explain additional variance. Table 6 presents the correlations between the four factors (also shown in Figure 4). Hearing acuity did not correlate much with the other predictors, except for processing speed. The other three predictors correlated moderately.

A number of additional analyses were performed. We tested a model in which the relationship between word recognition in unfiltered and filtered speech was reversed: the filtered speech factor was regressed onto the unfiltered speech factor. In this model presented in Table 7 , which fitted equally well, working memory was found to explain unique variance in the unfiltered speech factor beyond what was already explained by the filtered speech factor. This indicates that there is an interaction between working memory and type of word recognition: working memory explains individual differences in unfiltered word recognition accuracy significantly better than in filtered word recognition accuracy. We also tried models in which one or more of the predictors were simply removed, for example, to test whether vocabulary knowledge did explain variance in the absence of memory. However, neither 
Table 6. Correlations between the four predictor factors

\begin{tabular}{lccc}
\hline & Hearing & Working memory & Processing speed \\
\hline Working memory & -.21 & - & - \\
\hline Processing speed & .40 & -.45 & - \\
\hline Vocabulary knowledge & -.14 & .55 & -.40 \\
\hline
\end{tabular}

Table 7. Implied correlations and standardized regression weights of the latent factors with the dependent variable word recognition accuracy as obtained in the "reversed" model in which the relationship between word recognition in unfiltered and filtered performance was reversed

\begin{tabular}{|c|c|c|c|c|}
\hline \multirow[b]{2}{*}{ Predictors } & \multicolumn{2}{|c|}{$\begin{array}{l}\text { Word recognition } \\
\quad \text { filtered }\end{array}$} & \multicolumn{2}{|c|}{$\begin{array}{l}\text { Word recognition } \\
\text { unfiltered }\end{array}$} \\
\hline & $r$ & $\beta$ & $r$ & $\beta$ \\
\hline Hearing acuity & -.70 & -.64 & -.55 & - \\
\hline Working memory & .41 & .26 & .53 & .24 \\
\hline Processing speed & -.39 & - & -.39 & - \\
\hline Vocabulary knowledge & .24 & - & .31 & - \\
\hline Word recognition filtered & n.a. & n.a. & .80 & .71 \\
\hline Variance explained & \multicolumn{2}{|c|}{$55 \%$} & \multicolumn{2}{|c|}{$69 \%$} \\
\hline
\end{tabular}

vocabulary knowledge nor speed explained additional variance in the absence of either memory or hearing acuity.

Finally, we ran a model with age as an additional, fifth predictor. This model fitted the data well, too, $\chi^{2}(98)=118.40, p=.08, \chi^{2} / d f$ ratio $=1.21$, $\mathrm{CFI}=0.972$, and RMSEA $=0.045$, but the results did not change: age correlated with both word recognition factors (respectively -.54 and -.55 for recognition in unfiltered and filtered speech), but did not explain additional variance in the model. These results suggest that the effects of age on word recognition accuracy can be explained entirely by hearing acuity and working memory (as for correlations: between age and hearing construct: $r=.58, p<.001$; between age and working memory construct: $r=-.31, p<.01){ }^{1}$

\section{Discussion}

This study was set up to investigate the importance of hearing acuity, information processing speed, working memory, and vocabulary knowledge for older adults' recognition of single words taken from fast speech. Hearing acuity and working memory each predicted unique variance in word recognition accuracy, but not to the same extent in unfiltered and low-pass filtered speech. Hearing acuity was more predictive in low-pass filtered speech than in unfiltered speech, whereas working memory was more predictive in unfiltered speech than in low-pass filtered speech. Processing speed and vocabulary knowledge did not explain unique variance in 
word recognition, even though both correlated significantly with word recognition accuracy. Note that, even though hearing acuity and working memory accounted for a sizable part of the total variance in word recognition performance, a large part of the variance was still not accounted for (cf. Tables 5 and 7). This suggests that not all relevant factors have been captured in this study.

The contribution of stimulus audibility to word recognition was assessed in two ways: by manipulating audibility of the fast word stimuli through filtering and by relating the continuous variation in participants' hearing acuity to word recognition. The correlations between hearing acuity and word recognition accuracy confirm that hearing plays an important role in explaining individual differences in fastword recognition (as intensity level of stimulus presentation was fixed for all participants). Even in the unfiltered condition, the observed correlation between hearing and word recognition was quite strong $(r=-.60)$ in our participant sample of older adults. Hearing acuity in the sample was generally relatively good with 64 (out of 105) participants having only fairly mild hearing losses (high-frequency pure-tone averages of maximally $25 \mathrm{~dB} \mathrm{HL}$ ), and only seven participants having pure-tone averages exceeding $40 \mathrm{~dB}$ HL. This suggests that fast and reduced speech may be difficult to recognize and makes a substantial demand on someone's hearing acuity. The results also show that between-listener differences in stimulus audibility were more predictive in the filtered than in the unfiltered condition. The filtering likely removed audible information from the stimulus, compromising the ability to properly recognize the words even further. This led to poorer performance on the task, especially by those with poorer hearing. The results for the predictive power of hearing acuity thus largely follow from individual differences in stimulus audibility in the two listening conditions.

This study extends individual-differences findings by previous studies: several literature reviews (Akeroyd, 2008; Besser, Koelewijn, Zekveld, Kramer, \& Festen, 2013; Dryden et al., 2017) already showed that working memory is important for recognition of clearly articulated speech masked by noise, and our results suggest this is similarly true for the recognition of words taken from fast speech. The results also align with findings by Dryden et al. (2017) on the predictive role of working memory across test materials: memory plays an important role for recognition at the lowest meaningful level, and not just at higher (sentence) levels of language processing where information needs to be integrated. However, contrary to our expectation, we did not find that working memory was more strongly implicated in acoustically more adverse listening conditions. The opposite was true: the associations between word recognition performance and memory were significantly weaker in the challenging condition, while the standard deviations of the mean recognition accuracies in both listening conditions were about equal, such that the weaker strength of the association between memory and word recognition performance in the filtered condition cannot be attributed to floor effects in performance.

A corollary of general capacity models of working memory is that working memory capacity is drawn on especially in situations when processing is more taxing (e.g., Baddeley, 2006; Just \& Carpenter, 1992; King \& Just, 1991; MacDonald et al., 1992). On the basis of the ELU model, one would predict that working memory capacity is more predictive of spoken language processing when listening conditions are more challenging (cf. Rönnberg, Rudner, Lunner, \& Zekveld, 2010). This 
argument was brought up earlier by Lunner and Sundewall-Thorén (2007), who observed that, at matched speech recognition performance levels, working memory was only associated with listening conditions assumed to be more demanding (modulated noise rather than unmodulated noise, and specific hearing-aid settings over others). To our knowledge, few studies have actually addressed the question of whether predictive power of working memory for speech recognition performance may differ across performance levels within the same listener group, and some have provided indecisive results (e.g., Heinrich \& Knight, 2016, whose results show an insignificant tendency for working memory to be more strongly associated with speech recognition at poorer performance levels).

One result that might be comparable is from a study by some authors of the ELU model on differential cognitive-capacity effects for hearing-impaired listeners at different performance levels (Rudner, Rönnberg, \& Lunner, 2011). This study investigated hearing-impaired listeners' recognition of speech in different noise masking conditions, and with different hearing-aid settings. In unaided listening conditions (i.e., when participants were not wearing their hearing aids) and when sentences were presented in stationary noise, participants with high working memory capacity outperformed participants with low working memory capacity in that the former group could stand more noise. Critically, this (working memory capacity) group difference in stationary-noise tolerance was only found at an $80 \%$ sentence accuracy level, but not at a $50 \%$ accuracy level. Results on the predictive power of working memory were again different for different types of noise masking and different hearing-aid settings, but the unaided stationary-noise listening conditions seems closest to our listening conditions, hence providing the most straightforward comparison.

Our finding that the association between working memory and speech recognition was stronger in the less adverse condition seems to fit better with working memory models that claim that there is no structural separation between working memory and long-term memory and that argue that working memory contains activated long-term memory information (e.g., Cowan, 2005; Ericsson \& Kintsch, 1995; MacDonald \& Christiansen, 2002). In these models, working memory capacity reflects the ability to activate long-term memory representations and to keep them active for ongoing processes, and they are thought to be mediated by the level of one's expertise or experience (e.g., Cowan, 2005; Ericsson \& Kintsch, 1995; Jones, Gobet, \& Pine, 2007; MacDonald \& Christiansen, 2002). High working memory scores should then be seen as resulting from high levels of verbal expertise rather than vice versa: participants who process (spoken) language efficiently may be able to score better on span measures of verbal working memory (such as reading span, digit span, and nonword repetition). A degraded acoustic signal would hinder spoken word processing and result in weaker correlations with working memory. Of the three working memory tasks administered, the nonword repetition task may measure the ability to hang on to auditory representations most closely, and was the memory measure that showed the strongest correlation with word recognition (Table 1). Note that the field of developmental language disorders has known a similar debate on the nature of the association between memory and language (cf. e.g., Bishop, Hardiman, \& Barry, 2012). In contrast to the widely held view that language problems in children with specific language impaiment may stem from auditory processing disorders, Bishop et al. argue, on the basis of SEM, that poor 
phonological memory skills (as quantified by nonword repetition performance) may be the cause, rather than the consequence, of impaired speech perception.

Vocabulary knowledge did not explain a significant amount of unique variance in fast-word recognition accuracy, and correlated significantly, but weakly. Reading research has argued that increased verbal expertise (operationalized by vocabulary size) leads to greater precision and stability of stored lexical representations (e.g., Andrews \& Hirsch, 2010; Yap et al., 2012), which would be advantageous for efficiently singling out target words from their competitors. Similarly, several recent papers have shown associations between receptive vocabulary and perception of noisy, accented speech (e.g., Banks et al., 2015) or between vocabulary and accented or disordered speech (e.g., Bent et al., 2016). Whereas the latter study did not include a working memory measure, such that no conclusion can be drawn on any unique variance accounted for by vocabulary, the results by Banks et al. specifically suggest that vocabulary directly predicts speech performance, and that the link between working memory and speech performance is mediated through vocabulary. The alternative structural models we tested in the present study did not provide any evidence for such mediation. This discrepancy in results could be due to multiple factors, such as the different statistical approach, which entailed that our working memory construct was based on three working memory measures, rather than on a single one (i.e., reading span in Banks et al., 2015). Alternatively, different results could be due to the choice of task and speech materials (identification of sentences vs. single words) or due to a different type of adverse listening condition (fast speech vs. noisy or accented speech), suggesting that some individual capacities (i.e., vocabulary) show up mainly in specific, rather than across, adverse listening conditions, which speaks to the recent debate on similar or differential associations between listener abilities and performance across different types of listening conditions (Bent, Baese-Berk et al., 2016; Borrie et al., 2017; McLaughlin et al., 2018).

Multiple studies (cf. Banks et al., 2015) have stressed the role of vocabulary knowledge in perceptual adaptation to novel input. Whereas working memory measures predicted accented-speech performance across trials, vocabulary was specifically related to the amount of adaptation to accented sentences across experimental trials (Janse \& Adank, 2012). Similarly, vocabulary knowledge, rather than working memory, predicted adaptation to noise-vocoded sentences in younger adults (Neger, Rietveld, \& Janse, 2014). Listeners may, to some degree, adapt to natural-fast speech as well (Adank \& Janse, 2009), but the present study, with its SEM approach, focused on general performance and on isolated word recognition, rather than on adaptation and sentence recognition. Further experimentation is required to find out whether vocabulary would be predictive of adaptation to fast speech.

Either way, both our results and the results by Banks et al. (2015) suggest the constructs of working memory and vocabulary to be overlapping constructs. This provides further confirmation for the idea that working memory capacity is domain specific and mediated by an individual's expertise or experience (e.g., Cowan, 2005). Correlations for vocabulary patterned similarly to those of working memory: the strongest correlation was found for word recognition accuracy in the unfiltered condition. Consequently, our results align with earlier observations that the contribution of cognitive/linguistic factors to speech recognition comes out more clearly once speech stimuli are sufficiently audible (e.g., Humes, 2007). 
Our study was also specifically set up to investigate whether processing speed facilitated word recognition, under the assumption that fast speech might bring out its role more clearly compared to other types of adverse listening conditions. Several studies have found that processing speed was a (substantial) predictor of word recognition accuracy (Dryden et al., 2017; Janse, 2009; Janse \& Newman, 2013; van Rooij \& Plomp, 1990), although this has not been a consistent result (Akeroyd, 2008). In the present study, processing speed correlated with word recognition; however processing speed did not explain variance beyond what was already explained by hearing acuity and working memory. Processing speed correlated substantially with both working memory $(r=-.40)$ and vocabulary $(r=-.45)$. The picture that emerges is that working memory, vocabulary, and processing speed are overlapping constructs: they could all be a proxy of verbal expertise, where working memory seems to be the most encompassing construct.

It should be noted, though, that processing speed may be more strongly related to speed of word recognition, which was not assessed in this offline study. With eyetracking research, it has been shown that the dynamics of spoken-word recognition (lexical activation, competition and decay, as evident from eye tracking research) differ between normal-hearing and hearing-impaired listeners (McMurray et al., 2017) and between control groups and adolescents with specific language impairment (McMurray et al., 2010). Of importance, these dynamics of spoken-word recognition also change instantly when normal-hearing listeners are presented with severely degraded speech (McMurray et al., 2017). Eye tracking research would be required to assess whether individual processing speed is associated with speed of lexical activation and competition, and hence with recognition speed, possibly particularly so in listening conditions with severely degraded signal quality. Note that the choice for a different listening task (such as eye tracking) would also enable us to include recognition of normal-rate speech, such that the potential association between processing speed and speech recognition can be compared for different speech rates.

Another explanation for the lack of an association with processing speed in our study may be that processing speed becomes more crucial when listeners are presented with sentences or passages, rather than single words. Participants may have been able to keep even the longest (four-syllable) words in auditory memory, such that information that could not be processed at a first pass was available for further decoding in later passes. Further experimentation is required to investigate whether processing speed does explain unique variance in speed and the dynamics of word recognition (e.g., specifically in rate of activation gain of the target word) or in processing of longer fragments.

In sum, individual differences in memory capacity are clearly associated with the ability to recognize words spoken in a fast and reduced way. Processing speed and vocabulary knowledge do not seem to uniquely contribute to word recognition accuracy. Recognition of single fast words thus does not seem to be facilitated by quick access to long-term memory representations. Generally, our results fit best with models of working memory that do not distinguish between working memory and long-term memory. They imply that verbal expertise (as indexed by verbal working memory or vocabulary knowledge) is associated with word recognition efficiency, and that the two may be two sides of the same coin. As argued above now that we have identified which capacities relate to spoken word recognition success, a 
next step would be to integrate these individual differences into (computationally implemented) models of spoken word recognition (e.g., Ten Bosch, Boves, \& Ernestus, 2015; Magnuson et al., 2020). Future research is needed to investigate how cognitive capacity exactly relates to speed of candidate activation and deactivation in spoken word perception in order to specify the role of cognitive capacity in models of spoken word recognition, for those with and without hearing problems, and possibly, to specify the role of language processing in working memory models.

\section{Note}

1. In a separate linear mixed-effects analysis, we investigated the effect of word frequency on recognition accuracy across the two listening conditions, and also tested for potential interactions between listener abilities and the word frequency effect. The results showed an interaction between word frequency and filtering, such that word frequency only affected recognition accuracy in the filtered (and not unfiltered) condition. Likewise, the only listener ability that interacted with the size of the word frequency effect was hearing acuity, such that word frequency affected recognition accuracy more for those with poorer hearing. Neither working memory nor vocabulary knowledge (nor speed) modulated the word frequency effect.

\section{References}

Adank, P., \& Janse, E. (2009). Perceptual learning of time-compressed and natural fast speech. Journal of the Acoustical Society of America, 126, 2649-2659.

Akeroyd, M. A. (2008). Are individual differences in speech reception related to individual differences in cognitive ability? A survey of twenty experimental studies with normal and hearing-impaired adults. International Journal of Audiology, 47, S53-S71.

Andrews, S., \& Hersch, J. (2010). Lexical precision in skilled readers: Individual differences in masked neighbor priming. Journal of Experimental Psychology: General, 139, 299-318.

Andringa, S., Olsthoorn, N., van Beuningen, C., Schoonen, R., \& Hulstijn, J. (2012). Determinants of success in native and non-native listening comprehension: An individual differences approach. Language Learning, 62, 49-78.

Baddeley, A. D. (2006). Working memory: An overview. In S. Pickering (Ed.), Working memory and education (pp. 1-31). New York: Academic Press.

Baddeley, A. D., Emslie, H., \& Nimmo-Smith, I. (1992). The speed and capacity of language processing (SCOLP) test. Bury St. Edmunds: Thames Valley Test Company.

Banks, B., Gowen, E., Munro, K. J., \& Adank, P. (2015). Cognitive predictors of perceptual adaptation to accented speech. Journal of the Acoustical Society of America, 137, 2015-2024.

Bates, T. C., Luciano, M., Montgomery, G. W., Wright, M. J., \& Martin, N. G. (2011). Genetic variance in a component of the language acquisition device: ROBO1 polymorphisms associated with phonological buffer deficits. Behavior Genetics, 41, 50-57.

Benard, M. R., Mensink, J. S., \& Başkent, D. (2014). Individual differences in top-down restoration of interrupted speech: Links to linguistic and cognitive abilities. Journal of the Acoustical Society of America, 135, EL88-EL94.

Bent, T., Baese-Berk, M., Borrie, S. A., \& McKee, M. (2016). Individual differences in the perception of regional, nonnative, and disordered speech varieties. Journal of the Acoustical Society of America, 140, 3775-3786.

Besser, J., Koelewijn, T., Zekveld, A. A., Kramer, S. E, \& Festen, J. M. (2013). How linguistic closure and verbal working memory relate to speech recognition in noise: A review. Trends in Amplification, 17, 75-93.

Bishop, D. V. M., Hardiman, M. J., \& Barry, J. G. (2012). Auditory deficit as a consequence rather than endophenotype of Specific Language Impairment: Electrophysiological evidence. PloS ONE, 7, e35851.

Borrie, S. A., Baese-Berk, M., van Engen, K., \& Bent, T. (2017). A relationship between processing speech in noise and dysarthric speech. Journal of the Acoustical Society of America, 141, 4660-4667.

Cowan, N. (2005). Working memory capacity. Hove, UK: Psychology Press. 
Daneman, M., \& Carpenter, P. A. (1980). Individual differences in working memory and reading. Journal of Verbal Learning \& Verbal Behaviour, 19, 450-466.

Daneman, M., \& Merikle, P. M. (1996). Working memory and language comprehension: A meta-analysis. Psychonomic Bulletin \& Review, 3, 422-433.

Deary, I. J., Johnson, W., \& Starr, J. M. (2010). Are processing speed tasks biomarkers of cognitive aging? Psychology and Aging, 25, 219-228.

Dryden, A., Allen, H. A., Henshaw, H., \& Heinrich, A. (2017). The association between cognitive performance and speech-in-noise perception for adult listeners: A systematic literature review and meta-analysis. Trends in Hearing, 21, 1-21.

de Jong, P. F., \& van der Leij, A. (1999). Specific contributions of phonological abilities to early reading acquisition: Results from a Dutch latent variable longitudinal study. Journal of Educational Psychology and Aging, 91, 450-476.

Earles, J. L., \& Salthouse, T. A. (1995). Interrelations of age, health, and speed. Journal of Gerontology: Psychological Sciences, 50B, 33-41.

Ericsson, K. A., \& Kintsch, W. (1995). Long-term working memory. Psychological Review, 102, 211-245.

Ernestus, M., Baayen, R. H., \& Schreuder, R. (2002). The recognition of reduced word forms. Brain and Language, 81, 162-173.

Farris-Trimble, A., McMurray, B., Cigrand, N., \& Tomblin, J. B. (2014). The process of spoken word recognition in the face of signal degradation. Journal of Experimental Psychology: Human Perception \& Performance, 40, 308-327.

Füllgrabe, C., \& Rosen, S. (2016). On the (un)importance of working memory in speech-in-noise processing for listeners with normal hearing thresholds. Frontiers in Psychology, 7, 8.

Gathercole, S. E. (2006). Nonword repetition and word learning: The nature of the relationship. Applied Psycholinguistics, 27, 513-543.

Gathercole, S. E., \& Baddeley, A. D. (1996). The Children's Test of Nonword Repetition. London: Psychological Corporation.

Gathercole, S. E., Willis, C. S., Baddeley, A. D., \& Emslie, H. (1994). The Children's Test of Nonword Repetition: A test of phonological working memory. Memory, 2, 103-127.

Goodboy, A. K., \& Kline, R. B. (2017). Statistical and practical concerns with published communication research featuring structural equation modeling. Communication Research Reports, 34, 68-77.

Hazenberg, S., \& Hulstijn, J. H. (1996). Defining a minimal receptive second-language vocabulary for non-native university students: An empirical investigation. Applied Linguistics, 17, 145-163.

Heinrich, A., \& Knight, S. (2016). The contribution of auditory and cognitive factors to intelligibility of words and sentences in noise. Advances in Experimental Medicine and Biology, 894, 37-45.

Hoyer, W. J., Stawski, R. S., Wasylyshyn, C., \& Verhaeghen, P. (2004). Adult age and digit symbol substitution performance: A meta-analysis. Psychology and Aging, 19, 211-214.

Hu, L. T., \& Bentler, P. M. (1999). Cutoff criteria for fit indexes in covariance structure analysis: Coventional criteria versus new alternatives. Structural Equation Modeling, 6, 1-55.

Humes, L. E. (2002). Factors underlying the speech recognition performance of elderly hearing-aid wearers. Journal of the Acoustical Society of America, 112, 1112-1132.

Humes, L. E. (2007). The contributions of audibility and cognitive factors to the benefit provided by amplified speech to older adults. Journal of the American Academy of Audiology, 18, 590-603.

Janse, E. (2004). Word perception in fast speech: Artificially time-compressed vs. naturally produced fast speech. Speech Communication, 42, 155-173.

Janse, E. (2009). Processing of fast speech by elderly listeners. Journal of the Acoustical Society of America, 125, 2361-2373.

Janse, E., \& Adank, P. (2012). Predicting foreign-accent adaptation in older adults. Quarterly Journal of Experimental Psychology, 65, 1563-1585.

Janse, E., \& Ernestus, M. (2011). The roles of bottom-up and top-down information in the recognition of reduced speech: Evidence from listeners with normal and impaired hearing. Journal of Phonetics, 39, 330-343.

Janse, E., \& Newman, R. (2013). Identifying nonwords: Effects of lexical neighborhoods, phonotactic probability, and listener characteristics. Language and Speech, 56, 421-441.

Janse, E., Nooteboom, S., \& Quené, H. (2007). Coping with gradient forms of /t/- deletion and lexical ambiguity in spoken word recognition. Language and Cognitive Processes, 22, 161-200. 
Jerger, J., Jerger, S., \& Pirozzolo, F. (1991). Correlational analysis of speech audiometric scores, hearing loss, age, and cognitive abilities in the elderly. Ear and Hearing, 12, 103-109.

Jones, G., Gobet, F., \& Pine, J. M. (2007). Linking working memory and long-term memory: A computational model of the learning of new words. Developmental Science, 10, 853-873.

Just, M. A., \& Carpenter, P. A. (1992). A capacity theory of comprehension. Psychological Review, 99, 122-149.

Keuleers, E., Brysbaert, M., \& New, B. (2010). SUBTLEX-NL: A new measure for Dutch word frequency based on film subtitles. Behavior Research Methods, 42, 643-650.

Kidd, E., Donnelly, S., \& Christiansen, M. H. (2018). Individual differences in language acquisition and processing. Trends in Cognitive Science, 22, 154-169.

King, J., \& Just, M. A. (1991). Individual differences in syntactic processing: The role of working memory. Journal of Memory and Language, 30, 580-602.

Kinoshita, S. (2006). Additive and interactive effects of word frequency and masked repetition in the lexical decision task. Psychonomic Bulletin \& Review, 13, 668-678.

Kline, R. B. (2005). Principles and practice of structural equation modeling. New York: Guilford Press.

Koch, X., \& Janse, E. (2016). Speech rate effects on the processing of conversational speech across the adult life span. Journal of the Acoustical Society of America, 139, 1618-1636.

Lemke, U., \& Zimprich, D. (2005). Longitudinal changes in memory and processing speed in old age. Aging, Neuropsychology and Cognition, 12, 57-77.

Lin, F. R., Thorpe, R., Gordon-Salant, S., \& Ferrucci, L. (2011). Hearing loss prevalence and risk factors among older adults in the United States. Journal of Gerontology: Medical Sciences, 66A, 582-590.

Luce, P. A., \& Pisoni, D. B. (1998). Recognizing spoken words: The Neighborhood Activation model. Ear and Hearing, 19, 1-36.

Lunner, T., \& Sundewall-Thorén, E. (2007). Interactions between cognition, compression, and listening conditions: Effects on speech-in-noise performance in a two-channel hearing aid. Journal of the American Academy of Audiology, 18, 539-552.

MacDonald, M. C., Just, M. A., \& Carpenter, P. A. (1992). Working memory constraints on the processing of syntactic ambiguity. Cognitive Psychology, 24, 56-98.

MacDonald, M. C., \& Christiansen, M. H. (2002). Reassessing working memory: A comment on Just \& Carpenter (1992) and Waters \& Caplan (1996). Psychological Review, 109, 35-54.

Magnuson, J. S., You, H., Luthra, S., Li, M., Nam, H., Escabí, M., . . Rueckl, J. G. (2020). EARSHOT: A minimal neural network model of incremental human speech recognition. Cognitive Science, 44, e12823.

McAuliffe, M. J., Gibson, E. M. R., Kerr, S. E., Anderson, T., \& LaShell, P. J. (2013). Vocabulary influences older and younger listeners' processing of dysarthric speech. Journal of the Acoustical Society of America, 134, 1358-1368.

McClelland, J. L., \& Elman, J. L. (1986). The TRACE model of speech perception. Cognitive Psychology, 18, $1-86$.

McGettigan, C., Warren, J. E., Eisner, F., Marshall, C. R., Shanmugalingam, P., Scott, S. K. (2011). Neural correlates of sublexical processing in phonological working memory. Journal of Cognitive Neuroscience, 23, 961-977.

McLaughlin, D. J., Baese-Berk, M. M., Bent, T., Borrie, S. A., \& van Engen, K. (2018). Coping with adversity: Individual differences in the perception of noisy and accented speech. Attention, Perception, \& Psychophysics, 80, 1559-1570.

McMurray, B., Samelson, V. M., Hee Lee, S., \& Tomblin, J. B. (2010). Individual differences in online spoken word recognition: Implications for SLI. Cognitive Psychology, 60, 1-39.

McMurray, B., Farris-Trimble, A., \& Rigler, H. (2017). Waiting for lexical access: Cochlear implants or severely degraded input lead listeners to process speech less incrementally. Cognition, 169, 147-164.

Middelweerd, M. J., Festen, J. M., \& Plomp, R. (1990). Difficulties with speech intelligibility in noise in spite of a normal pure-tone audiogram. Audiology, 29, 1-7.

Neger, T. M., Rietveld, T., \& Janse, E. (2014). Relationship between perceptual learning in speech and statistical learning in younger and older adults. Frontiers in Human Neuroscience, 8, 628.

Norris, D., \& McQueen, J. M. (2008). Shortlist B: A Bayesian model of continuous speech recognition. Psychological Review, 115, 357-395.

Perfetti, C. A. (1992). The representation problem in reading acquisition. In P. B. Gough, L. C. Ehri, \& R. Treiman (Eds.), Reading acquisition (pp. 145-174). Hillsdale, NJ: Erlbaum. 
Perfetti, C. A. (2007). Reading ability: Lexical quality to comprehension. Scientific Studies of Reading, 11, 357-383.

Perfetti, C. A., \& Hart, L. (2002). The lexical quality hypothesis. In L. Verhoeven, C. Elbro, \& P. Reitsma (Eds.), Precursors of functional literacy (pp. 189-213). Amsterdam: Benjamins.

Picheny, M. A., Durlach, N. I., \& Braida, L. D. (1985). Speaking clearly for the hard of hearing. I. Intelligibility differences between clear and conversational speech. Journal of Speech and Hearing Research, 28, 96-103.

Ramus, F., \& Szenkovits, G. (2008). What phonological deficit? Quarterly Journal of Experimental Psychology, 61, 129-141.

Ranbom, L. J., \& Connine, C. M. (2007). Lexical representation of phonological variation in spoken word recognition. Journal of Memory and Language, 57, 273-298.

Rönnberg, J., Danielsson, H., Rudner, M., Arlinger, S., Sternäng, O., Wahlin, A., \& Nilsson, L.-G. (2011). Hearing loss is negatively related to episodic and semantic long-term memory but not to short-term memory. Journal of Speech, Language and Hearing Research, 54, 705-726.

Rönnberg, J., Lunner, T., Zekveld, A., Sörqvist, P., Danielsson, H., Lyxell, B., . . Rudner, M. (2013). The ease of language understanding (ELU) model: Theoretical, empirical and clinical advances. Frontiers in Systems Neuroscience, 7, 31.

Rönnberg, J., Rudner, M., Foo, C., \& Lunner, T. (2008). Cognition counts: A working memory system for ease of language understanding (ELU). International Journal of Audiology, 47, S99-S105.

Rönnberg, J., Rudner, M., Lunner, T., \& Zekveld, A. A. (2010). When cognition kicks in: Working memory and speech understanding in noise. Noise \& Health, 12, 263-269.

Rudner, M., Rönnberg J., \& Lunner, T. (2011). Working memory supports listening in noise for persons with hearing impairment. Journal of the American Academy of Audiology, 22, 156-167.

Salthouse, T. A. (1996). The processing-speed theory of adult age differences in cognition. Psychological Review, 103, 403-428.

Schneider, W., Eschman, A., \& Zuccolotto, A. (2002). E-prime reference guide. Pittsburgh, PA: Psychology Software Tools.

Sommers, M. S. (1996). The structural organization of the mental lexicon and its contribution to age-related changes in spoken word recognition. Psychology and Aging, 11, 333-341.

Sommers, M. S., \& Danielson, S. M. (1999). Inhibitory processes and spoken word recognition in young and older adults: The interaction of lexical competition and semantic context. Psychology and Aging, 14, 458-472.

Taler, V., Aaron, G. P., Steinmetz, L. G., \& Pisoni, D. B. (2010). Lexical neighborhood density effects on spoken word recognition and production in healthy aging. Journal of Gerontology: Psychological Sciences, 65B, 551-560.

Tamati, T. N., Gilbert, J. L., \& Pisoni, D. B. (2013). Some factors underlying individual differences in speech recognition on PRESTO: A first report. Journal of the American Academy of Audiology, 24, 616-634.

Ten Bosch, L., Boves, L., \& Ernestus, M. (2015). DIANA, an end-to-end computational model of human word comprehension. In Scottish Consortium for ICPhS, M. Wolters, J. Livingstone, B. Beattie, R. Smith, M. MacMahon, et al. (Eds.), Proceedings of the 18th International Congress of Phonetic Sciences (ICPhS 2015). Glasgow: University of Glasgow Press.

Thorn, A. S. C., \& Gathercole, S. E. (1999). Language-specific knowledge and short-term memory in bilingual and non-bilingual children. Quarterly Journal of Experimental Psychology Section A, 52, 303-324.

Tucker, B. V. (2011). The effect of reduction on the processing of flaps and /g/ in isolated words. Journal of Phonetics, 39, 312-318.

van den Noort, M., Bosch, P., Haverkort, M., \& Hugdahl, K. (2008). A standard computerized version of the reading span test in different languages. European Journal of Psychological Assessment, 24, 35-42.

van Engen, K. J., Chandrasekaran, B., \& Smiljanic, R. (2012). Effects of speech clarity on recognition memory for spoken sentences. PLoS ONE, 7, e43753.

van Rooij, J. C. G. M., \& Plomp, R. (1990). Auditive and cognitive factors in speech perception by elderly listeners: II. Multivariate analyses. Journal of the Acoustical Society of America, 88, 2611-2624.

van Rooij, J. C. G. M., \& Plomp, R. (1992). Auditive and cognitive factors in speech perception by elderly listeners: III. Additional data and final discussion. Journal of the Acoustical Society of America, 91, $1028-1033$. 
Wechsler, D. (2004). Wechsler Adult Intelligence Test. (3rd ed., Dutch version). Amsterdam, Netherlands: Harcourt Test Publishers.

Yap, M. J., Balota, D. A., Sibley, D. E., \& Ratcliff, R. (2012). Individual differences in visual word recognition: Insights from the English lexicon project. Journal of Experimental Psychology: Human Perception and Performance, 38, 53-79.

Yap, M. J., Tse, C., \& Balota, D. A. (2009). Individual differences in the joint effects of semantic priming and word frequency revealed by RT distributional analyses: The role of lexical integrity. Journal of Memory and Language, 61, 303-325.

Zekveld, A. A., Rudner, M., Johnsrude, I. S., Festen, J. M., van Beek, J. H. M., \& Rönnberg, J. (2011). The influence of semantically related and unrelated text cues on the intelligibility of sentences in noise. Ear and Hearing, 32, 16-25.

Zekveld, A. A., Rudner, M., Johnsrude, I. S., Heslenfeld, D. J., \& Rönnberg, J. (2012). Behavioral and fMRI evidence that cognitive ability modulates the effect of semantic context on speech intelligibility. Brain and Language, 122, 103-113.

Cite this article: Janse, E. and Andringa, SJ. (2021). The roles of cognitive abilities and hearing acuity in older adults' recognition of words taken from fast and spectrally reduced speech. Applied Psycholinguistics 42, 763-790. https://doi.org/10.1017/S0142716421000047 